\title{
The dose-response relationship between tobacco smoking and the risk of lymphomas: a case-control study
}

\author{
Martina Taborelli ${ }^{1}$, Maurizio Montella ${ }^{2}$, Massimo Libra ${ }^{3}$, Rosamaria Tedeschi ${ }^{4}$, Anna Crispo ${ }^{2}$, Maria Grimaldi ${ }^{2}$, \\ Luigino Dal Maso ${ }^{1}$, Diego Serraino ${ }^{1}$ and Jerry Polesel ${ }^{1 *}$
}

\begin{abstract}
Background: Previous studies have provided limited support to the association between tobacco smoking and lymphomas with weak evidence of a dose-response relationship.

Methods: We investigated the relationship between tobacco smoking and risk of non-Hodgkin lymphomas (NHL) and Hodgkin lymphomas $(\mathrm{HL})$ through logistic regression spline models. Data were derived from an Italian hospitalbased case-control study (1999-2014), which enrolled 571 NHLs, 188 HLs, and 1004 cancer-free controls. Smoking habits and other lifestyle factors were assessed through a validated questionnaire. Odds ratios (OR) and 95\% confidence intervals $(\mathrm{Cl})$ were estimated by logistic regression, adjusting for potential confounders.

Results: Compared to never smokers, people smoking $\geq 15$ cigarettes/day showed increased risks of both NHL $(\mathrm{OR}=1.42,95 \% \mathrm{Cl}: 1.02,1.97)$ and $\mathrm{HL}(\mathrm{OR}=2.47,95 \% \mathrm{Cl}: 1.25,4.87)$; the risk was particularly elevated for follicular $\mathrm{NHL}(\mathrm{OR}=2.43 ; 95 \% \mathrm{Cl}: 1.31-4.51)$ and mixed cellularity $\mathrm{HL}(\mathrm{OR}=5.60,95 \% \mathrm{Cl}: 1.31,23.97)$. No excess risk emerged for former smokers or people smoking $<15$ cigarettes/day. Spline analyses showed a positive dose-response relationship with significant increases in NHL and HL risks starting from 15 and 21 cigarettes/day, respectively, with the most evident effects for follicular NHL and mixed cellularity HL. Smoking duration was significantly associated with the $\mathrm{HL}$ risk only $(\mathrm{OR}=2.15,95 \% \mathrm{Cl}: 1.16,3.99)$.
\end{abstract}

Conclusions: These findings support a role of tobacco smoking in the etiology of both $\mathrm{NHL}$ and $\mathrm{HL}$, providing evidence of a direct association of risk with smoking intensity.

Keywords: Case-control study, Dose-response relationship, Hodgkin lymphoma, Non-Hodgkin lymphoma, Spline models, Tobacco smoking

\section{Background}

In Europe, approximately 93,500 new cases of nonHodgkin lymphoma (NHL) and 17,500 of Hodgkin lymphoma (HL) were diagnosed in 2012 [1]. When combined, these two lymphoid malignancies represent the eighth most commonly diagnosed cancer in Europe (more than $3 \%$ of all new cancer cases), and the sixth in Italy [1].

The etiology of NHL and HL remains poorly understood with just few firmly established risk factors. Immune

\footnotetext{
* Correspondence: polesel@cro.it

'Unit of Cancer Epidemiology, CRO Aviano National Cancer Institute, via Franco Gallini 2, 33081 Aviano, PN, Italy

Full list of author information is available at the end of the article
}

suppression and viral infections are the most important risk factors for NHL and HL [2]; nonetheless, they are often related to specific histological subtypes [3], accounting for only a small proportion of the overall incidence of lymphomas [4, 5]. Notably, hepatitis $\mathrm{C}$ and -to a lesser extent- hepatitis B viruses, have been associated with NHL in several studies conducted in many countries [2], including Italy [6].

Tobacco smoking is a potential risk factor for NHL and HL worth scrutinizing. Several investigations have explored the role of tobacco smoking on the risk of NHL pointing to the etiologic heterogeneity among NHL subtypes [7, 8]. Indeed, it has been consistently shown that smoking may be associated only with certain 
NHL histological types, particularly follicular lymphoma (FL), with little evidence of a dose-response relationship $[7,9]$. Although some inconsistencies exist, results from previous investigations have generally supported a causal association between tobacco smoking and HL, highlighting a direct relationship between a higher number of cigarettes smoked per day and years of smoking and an increased risk of developing HL [8]. Although the evaluation of specific HL subtypes has been limited, most studies have reported that tobacco smoking is associated with an increased risk of mixed cellularity HL [10].

Because of limited results of epidemiological studies on the dose-response relationship between tobacco smoking and risk of lymphoma and its histological subtypes, we conducted a case-control study in three areas of Italy. To provide more accurate risk estimates than categorical analysis we used a flexible approach for the estimation of the dose-response relationship, applying regression spline models.

\section{Methods}

We analyzed data from two consecutive case-control studies on lymphomas, conducted with similar study protocols in two periods, 1999-2002 [11] and 2003-2014 [12].

\section{First study period, 1999-2002}

The study design and findings have been described elsewhere $[11,13,14]$. Briefly, the study conducted between 1999 and 2002 included 231 cases (median age: 59 years) with a new histologically confirmed diagnosis of NHL and 62 with HL (median age: 30 years). All cases were aged $\geq 18$ years and were enrolled in two National Cancer Institutes and general hospital in the province of Pordenone, northeastern Italy, and the town of Naples, southern Italy. Controls were 547 cancer-free inpatients frequencymatched according to center (Pordenone, Naples), gender, and age (in 5-year age groups) based on the distribution of overall study cases, which also included hepatocellular carcinomas (HCCs) [11, 13]. Data from this first study period were published in 2005 in form of odds ratios [11] and later, in 2014, included in a large publication of the InterLymph Consortium [3].

\section{Second study period, 2003-2014}

Between 2003 and 2014, we extended the previous study, focusing only on lymphomas, and maintaining the same study design, inclusion and exclusion criteria, and questionnaire. Cases were patients aged 18-84 years with incident, histologically confirmed diagnosis of NHL $(n=353$; median age: 56 years) or HL ( $n=130$, median age: 33 years). They were admitted to National Cancer Institutes and general hospitals in the province of Pordenone, northeastern Italy, and the towns of Naples and Catania, southern Italy. Five hundred thirty seven inpatients (median age: 50 years), admitted for a wide spectrum of acute, non-neoplastic conditions to the same hospitals as lymphomas cases, were enrolled as controls. They were frequency-matched by center (Pordenone, Naples, and Catania), gender, and age (in 5-year age groups) based on the distribution of all cases.

\section{Complete study dataset}

The small sample size of cases and controls collected separately in the first and second study periods (1999-2002; 2003-2014) did not allow to adequately address subgroup analyses or interactions [11]. Therefore, data from the two study periods were combined to improve statistical power so that the present analysis included $571 \mathrm{NHL}$ and $188 \mathrm{HL}$ cases with complete information on smoking status and blood samples. All cases were routinely tested for HIV, reporting negative results. Histological records were centrally revised, and lymphomas were classified according to the International Classification of Diseases for Oncology (third edition) [15]. Cancer-free patients admitted to hospitals for at least one of the following conditions were not eligible as controls: a) hematologic, allergic, or autoimmune disorders; b) diseases associated to tobacco consumption, alcohol abuse, or hepatitis viruses infections; c) chronic conditions that might have induce long-term changes in lifestyle habits. However, comorbidity for the above listed diseases was not an exclusion criterion. Overall, controls were admitted for the following reasons: nontraumatic orthopedic diseases (39.4\%); acute surgical conditions (20.9\%); trauma (20.4\%); eye diseases $(9.2 \%)$; other conditions (10.1\%).

The control group for NHL included 1004 inpatients with available blood samples. Since controls were matched also to HCC cases in the period 1999-2002, controls for NHL cases were more likely men and slightly younger than cases. Concerning HL cases, in view of their peculiar age distribution, a set of 188 subjects was selected from the pool of 1004 controls; one control was matched to each HL case according to center, year of enrolment, gender and age.

All study participants signed an informed consent, according to the requirements of the Board of Ethics of each study center, which approved the study.

\section{Questionnaire}

Trained interviewers administered a structured questionnaire to cases and controls during their hospital stay, thus reducing to $<5 \%$ the refusal rate of both cases and controls. The questionnaire included specific sections to assess information on socio-demographic indicators and tobacco consumption [11]. Information on smoking included smoking status (i.e., never, former, or current smoker), daily number of cigarettes/cigars and grams of pipe-tobacco smoked, age at starting and quitting, and duration of the habit. Smokers were defined as subjects who had smoked at least one cigarette per day for at 
least 12 months. Former smokers were those who had abstained from cigarette smoking for at least 12 months before the interviews. Considering the low prevalence of cigar and pipe smoking, in our computations, $1 \mathrm{~g}$ of pipe-smoked tobacco corresponded to one cigarette, and one cigar to three cigarettes. The validity and reproducibility of questions on self-reported smoking habits in our study population were satisfactory [16].

\section{Statistical methods}

The risk of NHL and HL was estimated through odds ratios (ORs) and corresponding 95\% confidence intervals (CIs), calculated by unconditional multiple logistic regression, including gender, age (in quinquennia plus a term for age as a continuous variable), study center, years of education, and place of birth [17]. Additional adjustment for alcohol drinking did not substantially modify risk estimates. Tests for trend were based on the likelihood-ratio test between the models with and without a linear term for each variable of interest. Tests for heterogeneity were computed by comparing the models with and without an interaction term [17].

The dose-response relationship between number of cigarettes/day and risk of NHL and HL was investigated using logistic regression spline models, and the appropriate pointwise CIs were also calculated [18]. Briefly, the logit was estimated through a generalized semiparametric model where the exposure (i.e., smoking intensity) was included as a smoothly piecewise polynomial of defined degree, with constrains for continuity at each join point. The optimal number of segments was detected putting an increasing number of knots and selecting the best-fitting model, defined as the one minimizing the Akaike Information Criterion [19]. ORs from spline models were estimated adjusting for the same factors as the unconditional multiple logistic regression, and "never smokers" were considered as the reference category. Moreover, to prevent estimates instability in the right tail due to sparse data, subjects who smoked $>30$ cigarettes/day were excluded: 7 NHL cases (1.6\%) and 15 relative controls (2.1\%); 9 HL cases (5.5\%).

Table 1 Distribution of cases of non-Hodgkin and Hodgkin lymphoma and controls according to selected characteristics

\begin{tabular}{|c|c|c|c|c|c|c|c|c|c|c|}
\hline & \multicolumn{5}{|c|}{ Non-Hodgkin lymphoma } & \multicolumn{5}{|c|}{ Hodgkin lymphoma } \\
\hline & \multicolumn{2}{|c|}{ Controls $(n=1004)$} & \multicolumn{2}{|c|}{ Cases $(n=571)$} & \multirow[t]{2}{*}{$p$-value ${ }^{a}$} & \multicolumn{2}{|c|}{ Controls $(n=188)$} & \multicolumn{2}{|c|}{ Cases $(n=188)$} & \multirow[t]{2}{*}{$p$-value ${ }^{\mathrm{a}}$} \\
\hline & $\overline{\text { No. }}$ & $\%$ & $\overline{\text { No. }}$ & $\%$ & & No. & $\%$ & $\overline{\text { No. }}$ & $\%$ & \\
\hline \multicolumn{11}{|l|}{ Study center } \\
\hline Aviano & 527 & 52.5 & 272 & 47.6 & & 83 & 44.1 & 83 & 44.1 & \\
\hline Napoli & 359 & 35.8 & 215 & 37.7 & & 56 & 29.8 & 56 & 29.8 & \\
\hline Catania & 118 & 11.7 & 84 & 14.7 & & 49 & 26.1 & 49 & 26.1 & \\
\hline \multicolumn{11}{|l|}{ Year of interview } \\
\hline 1999-2002 & 504 & 50.2 & 228 & 39.9 & & 62 & 33.0 & 63 & 34.0 & \\
\hline 2003-2014 & 500 & 49.8 & 343 & 60.1 & & 126 & 67.0 & 125 & 66.0 & \\
\hline \multicolumn{11}{|l|}{ Gender } \\
\hline Male & 622 & 62.0 & 318 & 55.7 & & 102 & 54.3 & 102 & 54.3 & \\
\hline Female & 382 & 38.0 & 253 & 44.3 & & 86 & 45.7 & 86 & 45.7 & \\
\hline \multicolumn{11}{|l|}{ Age (years) } \\
\hline$<30$ & 107 & 10.7 & 38 & 6.7 & & 66 & 35.1 & 78 & 41.5 & \\
\hline $30-44$ & 198 & 19.7 & 99 & 17.3 & & 79 & 42.0 & 67 & 35.6 & \\
\hline $45-64$ & 366 & 36.4 & 260 & 45.5 & & 35 & 18.6 & 35 & 18.6 & \\
\hline$\geq 65$ & 333 & 33.2 & 174 & 30.5 & & 8 & 4.3 & 8 & 4.3 & \\
\hline \multicolumn{11}{|l|}{ Place of birth ${ }^{b}$} \\
\hline North-Center & 487 & 48.6 & 221 & 38.8 & & 73 & 38.8 & 58 & 31.0 & \\
\hline South & 515 & 51.4 & 349 & 61.2 & $p<0.01$ & 115 & 61.2 & 129 & 69.0 & $p=0.13$ \\
\hline \multicolumn{11}{|c|}{ Education (years) ${ }^{b}$} \\
\hline$<7$ & 368 & 36.6 & 195 & 34.2 & & 18 & 9.6 & 21 & 11.2 & \\
\hline $7-11$ & 300 & 29.9 & 186 & 32.6 & & 73 & 38.8 & 64 & 34.2 & \\
\hline$\geq 12$ & 336 & 33.5 & 189 & 33.2 & $p=0.47$ & 97 & 51.6 & 102 & 54.6 & $p=0.62$ \\
\hline
\end{tabular}

${ }^{\mathrm{a} F i s h e r}$ test

${ }^{\mathrm{b}}$ The sum does not add up to the total because of missing values 


\section{Results}

Table 1 shows the distribution of cases and controls by study center, year of interview, gender, age, place of birth, and years of education. Compared to controls, NHL cases were more likely to be born in southern Italy. No differences emerged between HL cases and matched controls.

The association between tobacco smoking and risk of lymphoma is shown in Table 2. Among current smokers, no significant increase in NHL risk emerged, as compared to never smokers. Nevertheless, current heavy smokers (i.e., $\geq 15$ cigarettes/day) showed a higher NHL risk ( $\mathrm{OR}=1.42$, 95\% CI: 1.02, 1.97). Although not statistically significant, early age at starting smoking (i.e., <18 years) was associated with an increased NHL risk (OR $=1.36,95 \%$ CI: $0.99,1.88)$. A similar pattern of risk emerged for $\mathrm{HL}$, with an increased risk among current smokers who smoked more than 15 cigarettes/day (OR $=2.47,95 \% \mathrm{CI}: 1.25,4.87)$ as compared to never smokers (Table 2). Smoking duration of more than 15 years was also associated with an elevated HL risk $(\mathrm{OR}=2.15,95 \% \mathrm{CI}: 1.16,3.99)$. Conversely, among former smokers, smoking intensity, smoking duration, age at starting smoking, and time since quitting were not associated with the risk of either NHL or HL.

In the analysis by NHL histological subtypes (Table 3), only follicular NHL was significantly associated with heavy smoking $(\mathrm{OR}=2.43,95 \% \mathrm{CI}: 1.31,4.51)$. Nonetheless, other histological NHL subtypes reported increased risks, but the small sample size did not allow to draw conclusions. Regarding HL, heavy smoking was associated with a significantly increased risk of mixed cellularity $\mathrm{HL}(\mathrm{OR}=5.60,95 \% \mathrm{CI}: 1.31,23.97)$. Moreover, the ORs were 1.76 (95\% CI: 0.78, 3.98) for nodular sclerosis, and 3.22 (95\% CI: 1.15, 9.04) for other/NOS subtypes.

Considering the lack of any association among former smokers, the dose-response relationship between current tobacco smoking and lymphoma risk was investigated through spline models. The shape of best-fitting regression model showed that, for both NHL and HL, the risk steadily increased with increasing number of cigarettes/day above 10 and 15 cigarettes/day, respectively. However, the risk was significant beginning with 15 cigarettes/day (Fig. 1a) for NHL and 21 cigarettes/day for HL (Fig. 2a). Subgroup analyses for the main histological subtypes showed a significant increased risk of follicular NHL (Fig. 1c) after 7 cigarettes/ day, whereas the effect was less evident for diffuse large Bcell lymphomas (DLBCL) as the increase in risk turned out to be significant only after 22 cigarettes/day (Fig. 1b). Concerning HL subtypes, the risk of mixed cellularity HL (Fig. 2c) was significantly higher beginning with 20 cigarettes/ day. No significant dose-response relationship emerged for nodular sclerosis (Fig. 2b).

Table 4 shows the association between tobacco smoking and NHL risk in separate strata. No heterogeneity in risks emerged across strata of study center, gender, or age.

\section{Discussion}

The findings of this case-control study provided further evidence on the role of smoking in the etiology of both NHL and HL. The study reported positive dose-response relationships based on number of cigarettes smoked per day, highlighting an increase in NHL and HL risks beginning with 15 and 21 cigarettes/day, respectively. Age at smoking initiation was not significantly associated with either NHL or HL risk, whereas smoking duration was found to be significantly associated with the HL risk only.

Results from previous studies on tobacco smoking have not provided a definitive link with NHL [7, 8]. Even if some studies reported a positive dose-response association in terms of smoking intensity [11, 20, 21], most studies have not observed such a relationship [22-25]. Notably, in line with our results, a large pooled analysis of nine casecontrol studies from the InterLymph Consortium [26] found that heavy smokers had an elevated risk for NHL.

Although several studies have reported a positive association with smoking [27, 28], HL has never been regarded as a smoking-related cancer [7]. In agreement with our findings, a recent meta-analysis [8] evidenced a direct dose-response relationship between higher number of cigarettes smoked per day and number of years smoking, and increased risk of developing HL.

It is worth noting that most of the studies finding positive associations with HL have also observed null or inverse associations with NHL $[7,23,24]$. In the present investigation, the findings regarding HL were super imposable to those obtained for NHL -as no excess risk emerged among former or light smokers as compared to never smokers. Moreover, we found that the risk steadily increased with the number of cigarettes/day for both NHL and HL, yielding analogous effect estimates.

Stratification by subtypes revealed that cigarette smoking may affect risk differently, depending on the lymphoma subtypes. In agreement with our results, FL is the only NHL subtype with a statistically significant association reported consistently [7, 23, 25, 29]. The InterLymph Consortium [9] observed an increased risk of FL among current smokers, although no trend based on smoking intensity was evidenced. On the contrary, two cohort studies [23, 25] found an inverse association between smoking and risk of FL.

The majority of the investigations on smoking and HL lacked sample size and sometimes the histological information needed to distinguish among HL subtypes [23, 24 ]. Few reports have provided evidence for a role of tobacco smoking in the etiology of mixed cellularity HL $[10,27]$, in line with our results. Conversely, a European multi-center case-control study [28] showed that current smokers aged $\geq 35$ years had approximately a 2.5-fold higher risk of nodular sclerosis HL than never smokers with a suggestive dose-response relationship. 
Table 2 Risk of non-Hodgkin and Hodgkin lymphoma according to smoking habits

\begin{tabular}{|c|c|c|c|c|c|c|c|c|c|c|}
\hline & \multicolumn{5}{|c|}{ Non-Hodgkin lymphoma } & \multicolumn{5}{|c|}{ Hodgkin lymphoma } \\
\hline & \multicolumn{2}{|c|}{ Controls $(n=1004)$} & \multicolumn{2}{|c|}{ Cases $(n=571)$} & \multirow[t]{2}{*}{ OR $(95 \% \mathrm{Cl})$} & \multicolumn{2}{|c|}{ Controls $(n=188)$} & \multicolumn{2}{|c|}{ Cases $(n=188)$} & \multirow[t]{2}{*}{ OR $(95 \% \mathrm{Cl})$} \\
\hline & No. & $\%$ & No. & $\%$ & & No. & $\%$ & No. & $\%$ & \\
\hline \multicolumn{11}{|c|}{ Smoking status } \\
\hline Never & 426 & 42.4 & 239 & 41.9 & $1^{c}$ & 89 & 47.3 & 85 & 45.2 & $1^{c}$ \\
\hline Former & 296 & 29.5 & 146 & 25.6 & $0.91(0.68-1.20)$ & 33 & 17.6 & 23 & 12.2 & $0.83(0.43-1.63)$ \\
\hline Current & 282 & 28.1 & 186 & 32.6 & $1.18(0.91-1.54)$ & 66 & 35.1 & 80 & 42.6 & $1.50(0.93-2.44$ \\
\hline
\end{tabular}

Current

Smoking intensity (cig/day) $)^{a}$

\begin{tabular}{|c|c|c|c|c|c|c|c|c|c|c|}
\hline$<15$ & 141 & 14.0 & 78 & 13.7 & $0.99(0.71-1.39)$ & 40 & 21.3 & 36 & 19.2 & $1.07(0.61-1.88)$ \\
\hline$\geq 15$ & 139 & 13.8 & 108 & 18.9 & $1.42(1.02-1.97)$ & 26 & 13.8 & 43 & 22.9 & $2.47(1.25-4.87)$ \\
\hline \multicolumn{5}{|c|}{$x^{2}$ for trend } & \multicolumn{5}{|l|}{$p=0.04$} & $p=0.02$ \\
\hline \multicolumn{5}{|c|}{ Increase of 5 cig/day } & \multicolumn{5}{|l|}{$1.07(1.00-1.15)$} & $1.28(1.11-1.49)$ \\
\hline \multicolumn{11}{|c|}{ moking duration (years) ${ }^{a, b}$} \\
\hline$<30$ & 131 & 13.1 & 80 & 14.0 & $1.38(0.96-1.99)$ & 34 & 18.1 & 33 & 17.6 & $1.03(0.55-1.93)$ \\
\hline$\geq 30$ & 151 & 15.0 & 105 & 18.4 & $1.04(0.75-1.44)$ & 32 & 17.0 & 47 & 25.0 & $2.15(1.16-3.99)$ \\
\hline \multicolumn{5}{|c|}{$x^{2}$ for trend } & \multicolumn{5}{|l|}{$p=0.46$} & $p=0.03$ \\
\hline \multicolumn{11}{|c|}{ ge at starting (years) ${ }^{a}$} \\
\hline$\geq 18$ & 130 & 13.0 & 75 & 13.1 & $1.00(0.71-1.41)$ & 24 & 12.8 & 25 & 13.3 & $1.35(0.69-2.62)$ \\
\hline$<18$ & 151 & 15.0 & 110 & 19.3 & $1.36(0.99-1.88)$ & 42 & 22.3 & 55 & 29.3 & $1.60(0.93-2.77)$ \\
\hline \multicolumn{5}{|c|}{$x^{2}$ for trend } & \multicolumn{5}{|l|}{$p=0.07$} & $p=0.10$ \\
\hline
\end{tabular}

Former

Smoking intensity (cig/day) $)^{\text {a }}$

\begin{tabular}{|c|c|c|c|c|c|c|c|c|c|c|}
\hline$<15$ & 139 & 13.9 & 69 & 12.1 & $0.93(0.66-1.31)$ & 16 & 8.5 & 9 & 4.8 & $0.72(0.29-1.80)$ \\
\hline$\geq 15$ & 156 & 15.6 & 77 & 13.5 & $0.91(0.64-1.29)$ & 17 & 9.0 & 14 & 7.5 & $1.07(0.46-2.51)$ \\
\hline \multicolumn{5}{|c|}{$x^{2}$ for trend } & \multicolumn{5}{|l|}{$p=0.42$} & $p=0.49$ \\
\hline \multicolumn{5}{|c|}{ Increase of 5 cig/day } & \multicolumn{5}{|l|}{$0.99(0.92-1.06)$} & $1.02(0.83-1.24)$ \\
\hline
\end{tabular}

Smoking duration (years) $)^{a, b}$

\begin{tabular}{|c|c|c|c|c|c|c|c|c|c|c|}
\hline$<30$ & 168 & 16.7 & 86 & 15.1 & $0.95(0.69-1.31)$ & 12 & 6.4 & 14 & 7.5 & $1.56(0.66-3.72)$ \\
\hline$\geq 30$ & 127 & 12.7 & 60 & 10.5 & $0.85(0.58-1.25)$ & 20 & 10.6 & 9 & 4.8 & $0.44(0.17-1.13)$ \\
\hline$x^{2}$ for & & & & & $p=0.34$ & & & & & $p=0.83$ \\
\hline
\end{tabular}

Age at starting (years) $)^{a}$

\begin{tabular}{|c|c|c|c|c|c|c|c|c|c|c|}
\hline$\geq 18$ & 155 & 15.5 & 78 & 13.7 & $0.91(0.65-1.28)$ & 16 & 8.6 & 8 & 4.3 & $0.53(0.19-1.46)$ \\
\hline$<18$ & 139 & 13.9 & 65 & 11.4 & $0.87(0.61-1.26)$ & 16 & 8.6 & 15 & 8.0 & $1.17(0.52-2.62)$ \\
\hline \multicolumn{5}{|l|}{$x^{2}$ for trend } & \multicolumn{5}{|l|}{$p=0.36$} & $p=0.49$ \\
\hline \multicolumn{11}{|c|}{ ime since quitting (years) ${ }^{a}$} \\
\hline$\geq 16$ & 153 & 15.3 & 76 & 13.4 & $0.91(0.64-1.30)$ & 12 & 6.5 & 9 & 4.8 & $1.39(0.47-4.11)$ \\
\hline$<16$ & 140 & 14.0 & 67 & 11.8 & $0.86(0.60-1.23)$ & 19 & 10.2 & 13 & 7.0 & $1.10(0.47-2.53)$ \\
\hline \multicolumn{5}{|l|}{$x^{2}$ for trend } & \multicolumn{5}{|l|}{$p=0.39$} & $p=0.75$ \\
\hline
\end{tabular}

Odds ratios (OR) and $95 \%$ confidence intervals (Cl) were estimated using unconditional logistic regression model adjusted for gender, age, study center, years of education, and place of birth

${ }^{a}$ The sum does not add up to the total because of missing values. ${ }^{b}$ For $\mathrm{HL}$, the cut-off was set at 15 years

'Reference category 
Table 3 Risk of non-Hodgkin and Hodgkin lymphoma subtypes according to smoking habits

\begin{tabular}{|c|c|c|c|c|c|c|}
\hline & \multicolumn{5}{|c|}{ Smoking habits ${ }^{a}$} & \multirow{4}{*}{$\begin{array}{l}x^{2} \text { for } \\
\text { trend }\end{array}$} \\
\hline & \multirow{3}{*}{$\begin{array}{l}\text { Never }^{\text {b }} \\
\text { No. }\end{array}$} & \multicolumn{4}{|c|}{ Current } & \\
\hline & & \multicolumn{2}{|c|}{$<15$ cig/day } & \multicolumn{2}{|c|}{$\geq 15 \mathrm{cig} /$ day } & \\
\hline & & No. & OR $(95 \% \mathrm{Cl})$ & No. & $95 \% \mathrm{Cl}$ & \\
\hline \multicolumn{7}{|l|}{ Non-Hodgkin lymphoma } \\
\hline Mature B-cell lymphomas & 219 & 67 & $0.95(0.67-1.34)$ & 95 & $1.37(0.97-1.92)$ & $p=0.09$ \\
\hline DLBCL & 133 & 33 & $0.76(0.49-1.18)$ & 49 & $1.09(0.72-1.66)$ & $p=0.88$ \\
\hline Burkitt & 5 & 4 & $3.07(0.74-12.81)$ & 4 & $3.30(0.71-15.28)$ & $p=0.16$ \\
\hline Follicular & 39 & 18 & $1.31(0.69-2.47)$ & 25 & $2.43(1.31-4.51)$ & $p<0.01$ \\
\hline Mantle cell & 4 & 1 & $0.66(0.07-6.41)$ & 2 & $1.04(0.17-6.50)$ & $p=0.99$ \\
\hline Marginal zone & 16 & 3 & $0.66(0.18-2.44)$ & 4 & $1.09(0.33-3.66)$ & $p=0.80$ \\
\hline Lymphoplasmacytic & 8 & 3 & $1.56(0.38-6.48)$ & 2 & $0.87(0.16-4.86)$ & $p=0.99$ \\
\hline SLL/CLL & 8 & 4 & $1.41(0.40-4.93)$ & 7 & $2.47(0.81-7.59)$ & $p=0.06$ \\
\hline Other B-cell lymphomas & 6 & 1 & $0.45(0.05-4.15)$ & 2 & $2.87(0.41-20.02)$ & $p=0.46$ \\
\hline Mature T-cell lymphomas & 14 & 8 & $1.83(0.72-4.62)$ & 6 & $1.72(0.59-5.03)$ & $p=0.15$ \\
\hline Other or NOS & 6 & 3 & $1.20(0.75-1.91)$ & 7 & $2.30(1.40-3.77)$ & $p<0.01$ \\
\hline \multicolumn{7}{|l|}{ Hodgkin lymphoma } \\
\hline Nodular sclerosis & 61 & 28 & $1.14(0.61-2.12)$ & 18 & $1.76(0.78-3.98)$ & $p=0.23$ \\
\hline Mixed cellularity & 6 & 2 & $1.02(0.16-6.66)$ & 10 & $5.60(1.31-23.97)$ & $p=0.03$ \\
\hline Other or NOS & 18 & 6 & $0.78(0.27-2.21)$ & 15 & $3.22(1.15-9.04)$ & $p=0.06$ \\
\hline
\end{tabular}

Odds ratios (OR) and 95\% confidence intervals $(\mathrm{Cl})$ were estimated using unconditional logistic regression model adjusted for gender, age, study center, years of education, and place of birth

CLL Chronic lymphocytic leukemia, DLBCL Diffuse large B-cell lymphoma, NOS Not otherwise specified, SLL Small lymphocytic lymphoma

${ }^{\mathrm{a}}$ Former smokers excluded. ${ }^{\mathrm{b}}$ Reference category
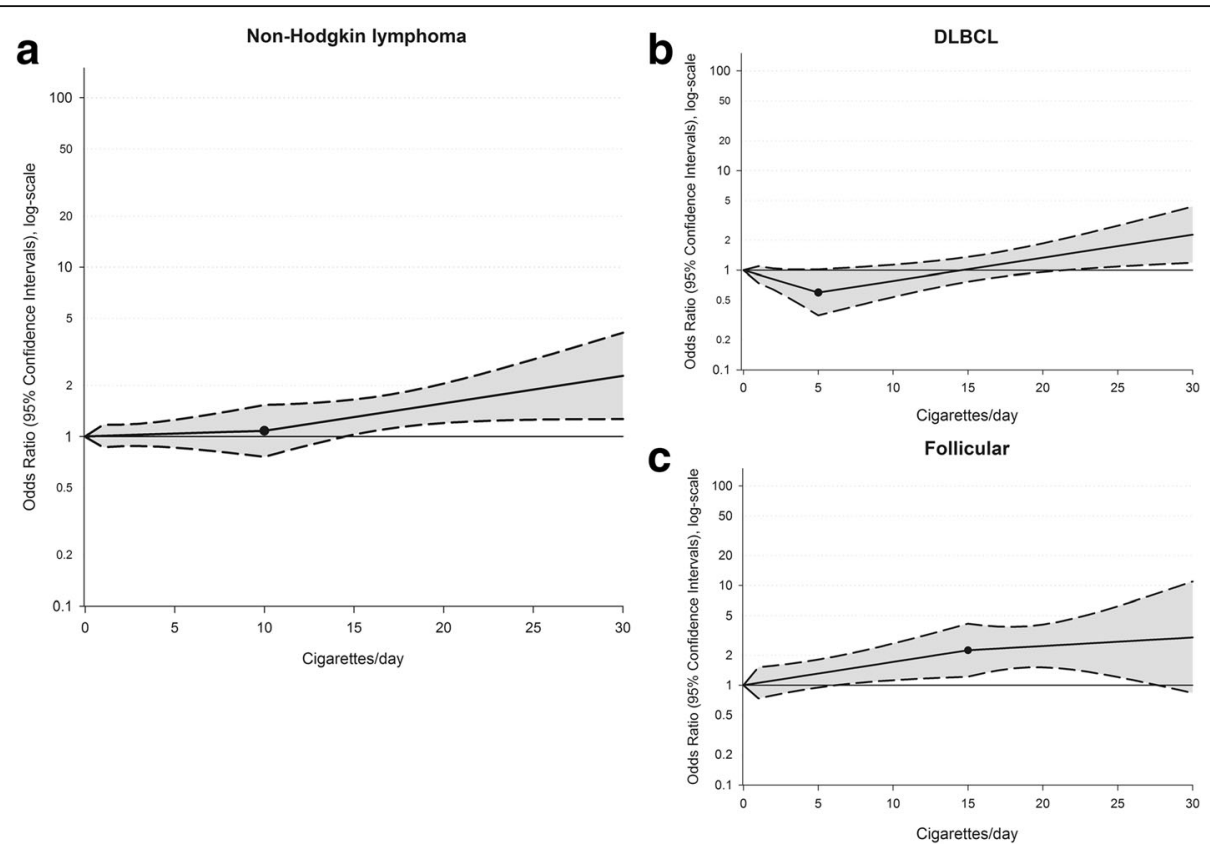

Fig. 1 Dose-response relationship between tobacco smoking and the risk of non-Hodgkin lymphoma a and its major subtypes: DLBCL $\mathbf{b}$ and follicular c Odds ratios and 95\% confidence intervals were estimated through logistic regression spline models adjusted for gender, age, study center, years of education, and place of birth. Curves are shown for best-fitting splines according to Akaike Information Criterion. The reference category was defined as never smokers. Filled circles show knot location 

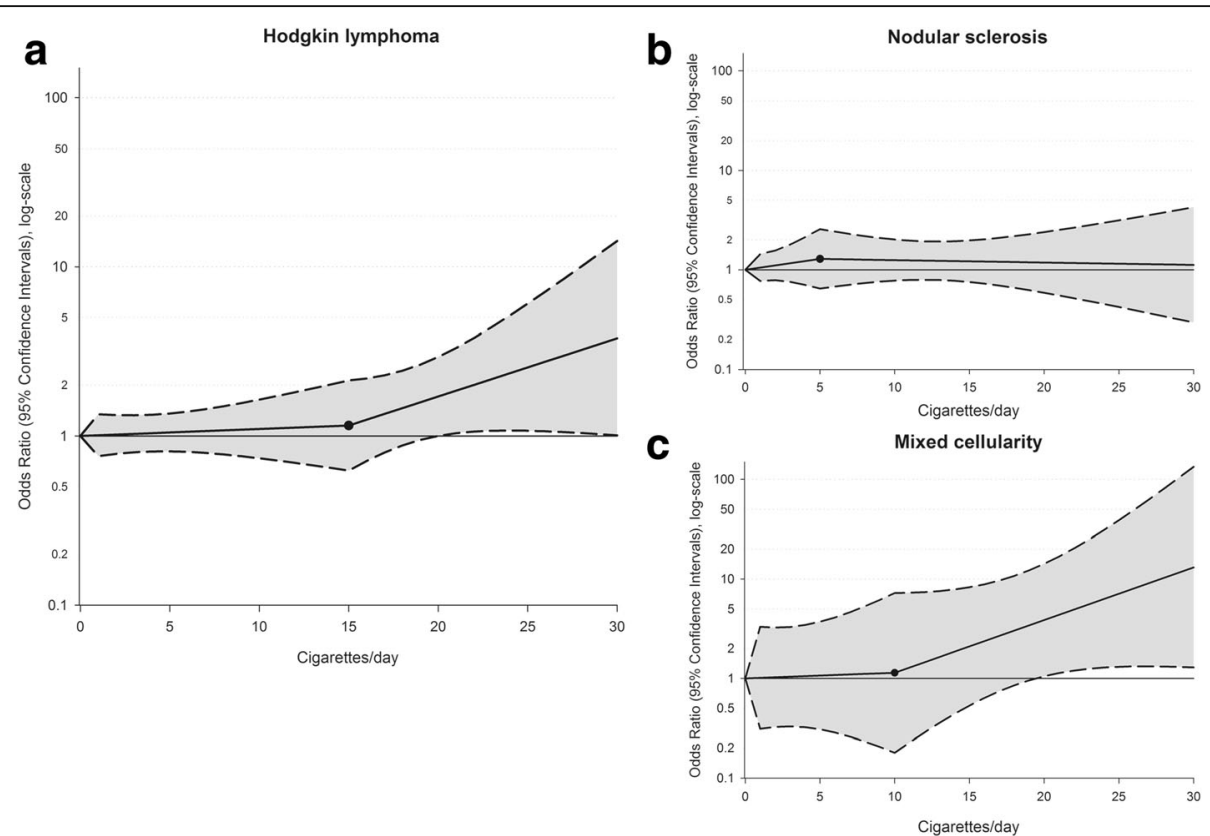

Fig. 2 Dose-response relationship between tobacco smoking and the risk of Hodgkin lymphoma a and its major subtypes: nodular sclerosis $\mathbf{b}$ and mixed cellularity c. Odds ratios and 95\% confidence intervals were estimated through logistic regression spline models adjusted for gender, age, study center, years of education, and place of birth. Curves are shown for best-fitting splines according to Akaike Information Criterion. The reference category was defined as never smokers. Filled circles show knot location

Table 4 Risk of non-Hodgkin lymphoma for smoking habits in selected strata

\begin{tabular}{|c|c|c|c|c|c|c|}
\hline & \multicolumn{5}{|c|}{ Smoking habits $^{a}$} & \multirow{3}{*}{$\begin{array}{l}X^{2} \text { for } \\
\text { trend }\end{array}$} \\
\hline & \multirow{2}{*}{$\begin{array}{l}\text { Never }^{b} \\
\text { Ca:Co }\end{array}$} & \multicolumn{2}{|c|}{ Current $<15$ cig/day } & \multicolumn{2}{|c|}{ Current $\geq 15$ cig/day } & \\
\hline & & $\overline{\mathrm{Ca}: \mathrm{Co}}$ & $95 \% \mathrm{Cl}$ & $\overline{\mathrm{Ca}: \mathrm{Co}}$ & $95 \% \mathrm{Cl}$ & \\
\hline \multicolumn{7}{|c|}{ Study center } \\
\hline Aviano & $133: 250$ & $33: 68$ & $1.08(0.70-1.68)$ & $30: 45$ & $1.56(0.95-2.56)$ & $p=0.57$ \\
\hline Napoli & $72: 128$ & $35: 53$ & $1.17(0.71-1.93)$ & $53: 60$ & $1.75(1.07-2.85)$ & $p=0.02$ \\
\hline \multirow[t]{2}{*}{ Catania } & $34: 48$ & $10: 20$ & $0.52(0.23-1.19)$ & $25: 34$ & $1.03(0.51-2.06)$ & $p=0.68$ \\
\hline & & & & & $x^{2}$ for heterogeneity $p$ & \\
\hline \multicolumn{7}{|l|}{ Gender } \\
\hline Male & $84: 186$ & $39: 83$ & $1.14(0.75-1.75)$ & $80: 119$ & $1.68(1.16-2.43)$ & $p=0.15$ \\
\hline \multirow[t]{2}{*}{ Female } & $155: 240$ & $39: 58$ & $0.98(0.63-1.51)$ & $28: 20$ & $1.67(0.91-3.07)$ & $p=0.06$ \\
\hline & & & & & $x^{2}$ for heterogeneity $p=$ & \\
\hline \multicolumn{7}{|l|}{ Age (years) } \\
\hline$<45$ & $66: 152$ & $22: 63$ & $1.11(0.70-1.76)$ & $34: 49$ & $2.33(1.39-3.89)$ & $p=0.01$ \\
\hline $45-64$ & $95: 136$ & $41: 52$ & $0.96(0.59-1.57)$ & $57: 66$ & $1.33(0.84-2.10)$ & $p=0.47$ \\
\hline \multirow[t]{2}{*}{$\geq 65$} & $78: 138$ & $15: 26$ & $1.20(0.57-2.51)$ & $17: 24$ & $1.31(0.61-2.80)$ & $p=0.64$ \\
\hline & & & & & $x^{2}$ for heterogeneity $p$ & \\
\hline
\end{tabular}

Odds ratios (OR) and 95\% Confidence Intervals (Cl) were estimated using unconditional logistic regression models adjusted for gender, age, study center, years of education, and place of birth. Ca, cases; Co, controls

${ }^{\text {a}}$ Former smokers excluded

${ }^{\mathrm{b}}$ Reference category 
The association between smoking and lymphoma found in this study is consistent with the evidence that direct carcinogenic effects of smoking are mediated by various chemicals contained in cigarettes such as formaldehyde [30] and benzene [31]. Moreover, smoking may also indirectly affect lymphomagenesis by modulating immune responses [32]. In fact, smoking has been shown to increase lymphocyte subset counts, alter their function, and to down-regulate the activity of natural killer cells and macrophages, thus promoting the pathogenesis of lymphomas [33].

The association of tobacco smoking with HL may be related to an effect of Epstein-Barr virus (EBV) reactivation due to the state of immunodeficiency induced by cigarette smoking [34]. Interestingly, in the present investigation, the association between current smoking and HL was restricted to the mixed cellularity subtype, which is more commonly associated with EBV [2]. Similarly, a pooled analysis from the InterLymph Consortium [10] have reported a higher risk for mixed cellularity and EBVpositive HL among current cigarette smokers in both younger and older individuals and among men. Moreover, a recent survey conducted among young male adults has observed that seroprevalence of EBV was higher among current smokers (93\%) than among never smokers (85\%) [35].

Some study limitations have to be acknowledged. First, selection and information biases were possible, as in most of hospital-based case-control studies. However, selection bias was limited by paying attention in: a) enrolling cases and controls in the same catchment areas; b) excluding from the control group all patients admitted to hospital for diseases associated to the exposures under study. Information bias, if any, is likely to have had a limited impact on study findings. Indeed, although cases and controls may have recalled their smoking habits differently, awareness of any particular hypothesis about the role of tobacco smoking in lymphomas' aetiology was limited in our study population at the time the study was conducted. Further, information bias has been minimized by the administration of the questionnaire to both cases and controls under similar conditions. Second, despite the relatively large sample size, the study has still limited power to detect association for specific NHL subtypes and results should be interpreted with caution. The nearly complete participation of identified cases and controls, the satisfactory reproducibility of information on tobacco smoking [16], and the revision of lymphoma diagnosis represent important strengths of our study. Finally, the choice of a more flexible approach for the estimation of the doseresponse relationship, such as regression spline models, allowed us to provide more accurate risk estimates than the categorical analysis.

\section{Conclusions}

In conclusion, our results lent additional support to the possibility that tobacco smoking may play a role in the etiology of both NHL and HL, including the HL subtype more commonly associated with EBV. Moreover, the risk of lymphoma appears to be elevated in people reporting a higher number of cigarettes smoked per day. Future studies would greatly benefit from a joint assessment of smoking parameters and biomarkers of infectious agents.

\section{Abbreviations \\ Cl: Confidence interval; DLBCL: Diffuse large B-cell lymphoma; EBV: Epstein- Barr virus; FL: Follicular lymphoma; HCC: Hepatocellular carcinoma; HL: Hodgkin lymphoma; NHL: Non-Hodgkin lymphoma; OR: Odds ratio}

\section{Acknowledgments \\ The authors wish to thank Mrs. Luigina Mei for editorial assistance.}

\section{Funding}

This work was partially supported by the Italian Association for the Research on Cancer (AIRC), Grant number 10447.

\section{Availability of data and materials}

The study dataset is available upon request for research purposes only, under a data transfer agreement, from the Unit of Cancer Epidemiology, CRO Aviano National Cancer Institute.

\section{Authors' contributions \\ JP, MM, and DS conceived the study; AC, MG, ML, and LDM coordinated patients' enrolment in each study centre, assuring that patients' eligibility was satisfied and carrying on controls' matching; RT conducted the serological testing; MT conducted the statistical analyses; AC and LDM provided support in the interpretation of results; MT and JP drafted the manuscript. All the Authors have critically revised the manuscript for important intellectual content and have given final approval of the version to be published.}

\section{Competing interests}

The authors declare that they have no competing interests.

\section{Consent for publication}

Not applicable

Ethical approval and consent to participate

The study protocol was approved by the Board of Ethics of each study center (namely, "Comitato Etico dell'IRCCS Centro di Riferimento Oncologico di Aviano", "Comitato Etico dell'IRCCS Fondazione Pascale", "Comitato Etico dell'Università degli Studi di Catania") according to laws and regulations in force at the time the study was conducted. All study participants signed a written informed consent.

\section{Publisher's Note}

Springer Nature remains neutral with regard to jurisdictional claims in published maps and institutional affiliations.

\section{Author details}

${ }^{1}$ Unit of Cancer Epidemiology, CRO Aviano National Cancer Institute, via Franco Gallini 2, 33081 Aviano, PN, Italy. ${ }^{2}$ Unit of Epidemiology, National Cancer Institute "G. Pascale" Foundation, via Marino Semmola, 80131 Naples, Italy. ${ }^{3}$ Department of Biomedical and Biotechnological Sciences (Biometec), University of Catania, via Androne 83, 95124 Catania, Italy. ${ }^{4}$ Unit of Microbiology, Immunology and Virology, via Franco Gallini 2, 33081 Aviano, PN, Italy. 
Received: 22 September 2016 Accepted: 8 June 2017

Published online: 16 June 2017

\section{References}

1. Ferlay J, Soerjomataram I, Ervik M, Dikshit R, Eser S, Mathers C, et al. GLOBOCAN 2012 v1.0, cancer incidence and mortality worldwide: IARC CancerBase no. 11. International Agency for Research on Cancer: Lyon, France; 2013. http://globocan.iarc.fr . Accessed 14 June 2017.

2. International Agency for Research on Cancer. IARC monographs on the evaluation of carcinogenic risks to humans. Vol. 100. A review of human carcinogens, Part B: Biological agents. Lyon, France: International Agency for Research on Cancer; 2012.

3. Morton LM, Slager SL, Cerhan JR, Wang SS, Vajidic CM, Skibola CF, et al. Etiologic heterogeneity among non-Hodgkin lymphoma subtypes: the InterLymph non-Hodgkin lymphoma subtypes project. J Natl Cancer Inst Monographs. 2014;2014:130-44

4. Cartwright RA, Watkins G. Epidemiology of Hodgkin's disease: a review. Hematol Oncol. 2004;22:11-26.

5. Alexander DD, Mink PJ, Adami H-O, Chang ET, Cole P, Mandel JS, et al. The non-Hodgkin lymphomas: a review of the epidemiologic literature. Int J Cancer. 2007;120(Suppl 12):1-39.

6. Dalia S, Chavez J, Castillo JJ, Sokol L. Hepatitis B infection increases the risk of non-Hodgkin lymphoma: a meta-analysis of observational studies. Leuk Res. 2013:37:1107-15.

7. International Agency for Research on Cancer. IARC monographs on the evaluation of carcinogenic risks to humans. Vol. 100. A review of human carcinogens, Part E: Personal Habits and Indoor Combustions. Lyon, France: International Agency for Research on Cancer; 2012.

8. Sergentanis TN, Kanavidis P, Michelakos T, Petridou ET. Cigarette smoking and risk of lymphoma in adults: a comprehensive meta-analysis on Hodgkin and non-Hodgkin disease. Eur J Cancer Prev. 2013;22:131-50.

9. Linet MS, Vajdic CM, Morton LM, de Roos AJ, Skibola CF, Boffetta P, et al Medical history, lifestyle, gamily history, and occupational risk factors for follicular lymphoma: the InterLymph non-Hodgkin lymphoma subtypes project. J Natl Cancer Inst. 2014:48:26-40.

10. Kamper-Jørgensen M, Rostgaard K, Glaser SL, Zahm SH, Cozen W, Smebdy $\mathrm{KE}$, et al. Cigarette smoking and risk of Hodgkin lymphoma and its subtypes: a pooled analysis from the International lymphoma Epidemiology Consortium (InterLymph). Ann Oncol. 2013;24:2245-55.

11. Talamini R, Polesel J, Montella M, Dal Maso L, Crispo A, Spina M, et al. Smoking and non-Hodgkin lymphoma: case-control study in Italy. Int J Cancer. 2005;115:606-10

12. Taborelli M, Polesel J, Montella M, Libra M, Tedeschi R, Battiston M, et al. Hepatitis B and C viruses and risk of non-Hodgkin lymphoma: a case-control study in Italy. Infect Agents Cancer. 2016;11:27

13. Franceschi S, Montella M, Polesel J, La Vecchia C, Crispo A, Dal Maso L, et al. Hepatitis viruses, alcohol, and tobacco smoking in the etiology of hepatocellular carcinoma in Italy. Cancer Epidemiol Biomark Prev. 2006:15:683-9.

14. Dal Maso L, Talamini R, Montella M, Crovatto M, Franceschi S. Hepatitis B and $\mathrm{C}$ viruses and Hodgkin lymphoma: a case-control study from northern and southern Italy. Haematologica. 2004;89:ELT17.

15. World Health Organization. International classification of diseases for oncology, third edition, first revision. Geneva: World Health Organization; 2013.

16. D'Avanzo B, La Vecchia C, Katsouyanni K, Negri E, Trichopoulos D. Reliability of information on cigarette smoking and beverage consumption provided by hospital controls. Epidemiology. 1996;7:312-5.

17. Breslow NE, Day NE. Statistical methods in cancer research Vol. I: the analysis of case-controls studies. IARC scientific publication no 32. International Agency for Research on Cancer: Lyon, France; 1980.

18. Dal Maso L, Torelli N, Biancotto E, Di Maso M, Gini A, Franchin G, et al. Combined effect of tobacco smoking and alcohol drinking in the risk of head and neck cancers: a re-analysis of case-control studies using bi-dimensional spline models. Eur J Epidemiol. 2016;31:385-93.

19. Akaike $H$. Information theory and an extension of the maximum likelihood principle. In: Petrov BN, Csàki F, editors. Second symposium on information theory. Akademiai Kiàdo: Budapest; 1973. p. 267-81.

20. Kanda J, Matsuo K, Kawase T, Suzuki T, Ichinohe T, Setu M, et al. Association of alcohol intake and smoking with malignant lymphoma risk in Japanese: a hospital-based case-control ctudy at Aichi cancer center. Cancer Epidemio Biomark Prev. 2009;18:2436-41.
21. Kroll ME, Murphy F, Pirie K, Reeves GK, Green J, Beral V, et al. Alcohol drinking, tobacco smoking and subtypes of haematological malignancy in the UK million women study. Br J Cancer. 2012;107:879-87.

22. Besson H, Brennan P, Becker N, Nieters A, De Sanjosé S, Font R, et al. Tobacco smoking, alcohol drinking and non-Hodgkin's lymphoma: a European multicenter case-control study (Epilymph). Int J Cancer. 2006;119:901-8.

23. Lim U, Morton LM, Subar AF, Baris D, Stolzenberg-Solomon R, Leitsman $M$, et al. Alcohol, smoking, and body size in relation to incident Hodgkin's and non-Hodgkin's lymphoma risk. Am J Epidemiol. 2007; 166:697-708

24. Nieters A, Rohrmann S, Becker N, Linseisen J, Ruediger T, Overvad K, et al. Smoking and lymphoma risk in the European prospective investigation into cancer and nutrition. Am J Epidemiol. 2008;167:1081-9.

25. Troy JD, Hartge P, Weissfeld JL, Oken MM, Colditz GA, Mechanic LE, et al. Associations between anthropometry, cigarette smoking, alcohol consumption, and non-Hodgkin lymphoma in the prostate, lung, colorectal, and ovarian cancer screening trial. Am J Epidemiol. 2010;171:1270-81.

26. Morton LM, Hartge P, Holford TR, Holle EA, Chiu BC, Vineis $P$, et al. Cigarette smoking and risk of non-Hodgkin lymphoma: a pooled analysis from the International lymphoma Epidemiology Consortium (InterLymph). Cancer Epidemiol Biomark Prev. 2005;14:925-33.

27. Briggs NC, Hall HI, Brann EA, Moriarty CJ, Levine RS. Cigarette smoking and risk of Hodgkin's disease: a population-based case-control study. Am J Epidemiol. 2002;156:1011-20.

28. Besson H, Brennan P, Becker N, De Sanjosé S, Nieters A, Font R, et al. Tobacco smoking, alcohol drinking and Hodgkin's lymphoma: a European multi-center case-control study (EPILYMPH). Br J Cancer. 2006;95:378-84.

29. Stagnaro E, Tumino R, Parodi S, Crosignani P, Fontana A, Masala G, et al. Non-Hodgkin's lymphoma and type of tobacco smoke. Cancer Epidemiol Biomark Prev. 2004;13:431-7.

30. Blair A, Stewart P, O'Berg M, Gaffey W, Walrath J, Ward J, et al. Mortality among industrial workers exposed to formaldehyde. J Natl Cancer Inst. 1986;76:1071-84.

31. Miligi L, Costantini AS, Benvenuti A, Kriebel D, Bolejack V, Tumino R, et al. Occupational exposure to solvents and the risk of lymphomas. Epidemiology. 2006;17:552-61.

32. Sopori M. Effects of cigarette smoke on the immune system. Nat Rev Immunol. 2002;2:372-7.

33. Sopori ML, Kozak W. Immunomodulatory effects of cigarette smoke. J Neuroimmunol. 1998;83:148-56.

34. Hjalgrim H, Ekström-Smedby K, Rostgaard K, Amini RM, Molin D, Hamilton-Dutoit $\mathrm{S}$, et al. Cigarette smoking and risk of Hodgkin lymphoma: a population-based case-control study. Cancer Epidemiol Biomark Prev. 2007;16:1561-6.

35. Levine H, Balicer RD, Rozhavski V, Halperin T, Shreberk M, Davidovitch N, et al. Seroepidemiology of Epstein-Barr virus and cytomegalovirus among Israeli male young adults. Ann Epidemiol. 2012;22:783-8.

\section{Submit your next manuscript to BioMed Central and we will help you at every step:}

- We accept pre-submission inquiries

- Our selector tool helps you to find the most relevant journal

- We provide round the clock customer support

- Convenient online submission

- Thorough peer review

- Inclusion in PubMed and all major indexing services

- Maximum visibility for your research

Submit your manuscript at www.biomedcentral.com/submit
) Biomed Central 